\title{
Zecke im Ohr
}

Im Juni 2008 suchte eine 47-jährige Frau wegen seit einem Tag bestehender knackender Geräusche im linken Ohr eine Nothilfe auf. Bei der Otoskopie erkannte man auf dem linken Trommelfell eine Zecke (siehe Abbildung). Ein HNO-Arzt entfernte das Tier unter Sicht mit einer Zange. Sofort verschwand das Knacken im Ohr. Zu Blutungen, einem Hörverlust oder einer Perforation des Trommelfells kam es nicht.

- Bei der genaueren Untersuchung erwies sich das Tier als Dermacentor variabilis, bekannter unter dem Namen amerikanische Hundezecke. Die Patientin lebte in einer ländlichen Region des Bundesstaates Minnesota wo die durch Zecken übertragene Borreliose endemisch ist. Sie erinnerte sich nicht an einen Zeckenstich, berichtete aber, dass ihr Hund oft in ihrem Schlafzimmer auf dem Boden schlief.

- C A Grady et al.

(pitt.bobbi@mayo.edu): Dermacentor tick attached to tympanic membrane. Lancet 378 (2011) 9788,347

\section{Kommentar}

D. variables ist kein primärer Vektor von $B$. burgdorferi und Anaplasma phagocytophilum, den Erregern der Lyme-Krankheit und der humanen Anaplasmose. Diese Zecke überträgt aber das Rocky-MountainFleckfieber und die Tularämie. Zum Glück für

die Patientin kommen diese Erkrankungen allerdings in Minnesota praktisch nicht vor. Beim Gedanken daran, eine Zecke auf dem Trommelfell sitzen zu haben, kann einem aber doch Hören und Sehen vergehen.

H. S. FÜESSL

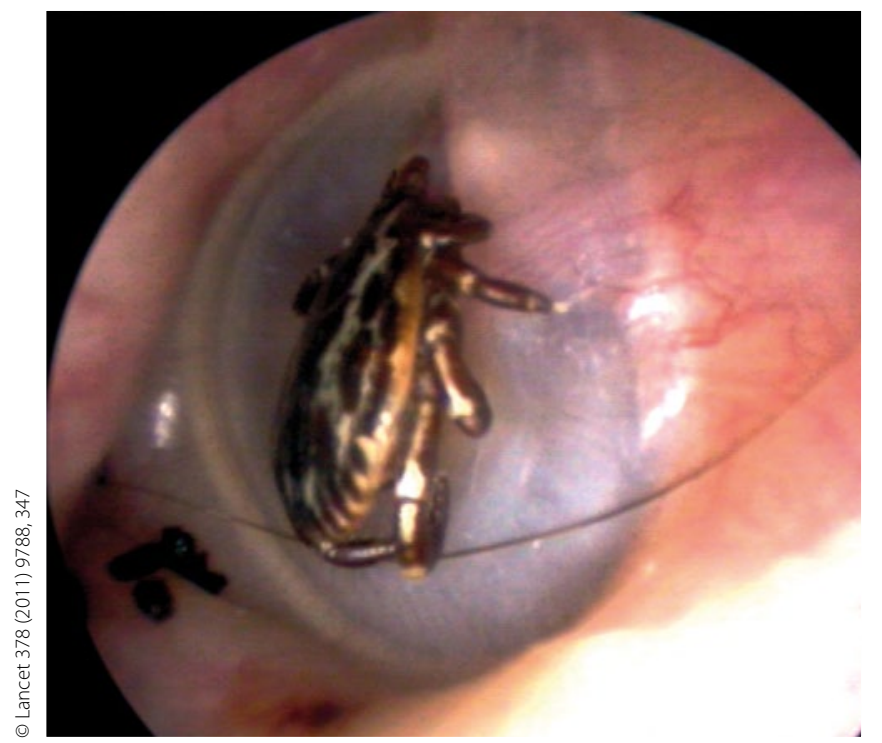

Was hat Dermacentor variabilis im Ohr verloren? 